\title{
Dextrose $10 \%$ Drink is Superior than Sodium Dextrose in Increasing Blood Glucose and Sprint Speed in Soccer Players: a Double-Blinded Randomized Crossover Trial Study
}

Agussalim Bukhari ( $\square$ agussalim.bukhari@med.unhas.ac.id)

Universitas Hasanuddin

\section{Suryani As'ad}

Universitas Hasanuddin

Nurpudji A Taslim

Universitas Hasanuddin

Mushawwir Thaiyeb

Universitas Negeri Makassar

Ignatius Yuwanda Chrissander

Universitas Hasanuddin https://orcid.org/0000-0002-2434-6888

Febryan Agus Pramudyo

Universitas Hasanuddin

\section{Original Research Article}

Keywords: Ergogenic effect, ergogenic aid, male soccer players, blood glucose level, sprint speed, V02max, dextrose

Posted Date: July 14th, 2020

DOI: https://doi.org/10.21203/rs.3.rs-40968/v1

License: (9) This work is licensed under a Creative Commons Attribution 4.0 International License. Read Full License

Version of Record: A version of this preprint was published at Science \& Sports on April 1st, 2021. See the published version at https://doi.org/10.1016/j.scispo.2020.11.008. 


\section{Abstract}

Background: Sports drink should be formulated to be effective in improving sports performance, but there is no standard of agreement about the most effective formulation. The diversity of situations in which these drinks are used for and the various factors might contribute to its specific efficacy. The main elements of a sports drink are water, sugar and salt. The major constituents which can be manipulated to alter the functional effects of sports drinks are the carbohydrate $(\mathrm{CHO})$ concentration, type and the electrolyte content. The solution of either dextrose (D) 4-8\% or sodium dextrose (Na-D) are able to increase the blood glucose (BG). However, there are still no comparison about the differences in effects between solely $D$ versus Na-D on soccer players. The aim of this study was to examine the effect of $D$ supplementation on $\mathrm{BG}, \mathrm{VO}_{2} \mathrm{max}$, and sprint speed compared with $\mathrm{Na}-\mathrm{D}$.

Method: We conducted a double-blinded crossover study of a 22 young male ( $19 \pm 1.1$ years) soccer players, consumed either $\mathrm{D}$ or $\mathrm{Na}-\mathrm{D}$ fluid. We compared pre and post data of $\mathrm{BG}, \mathrm{VO}_{2}$ max and sprint speed between $D$ and $\mathrm{Na}-\mathrm{D}$ group. The primary outcome was differences in $\triangle \mathrm{BG}$ between $\mathrm{D}$ and $\mathrm{Na}-\mathrm{D}$ group. Secondary outcomes were differences in $\Delta \mathrm{VO}_{2}$ max and $\Delta$ sprint speed between $\mathrm{D}$ and $\mathrm{Na}$-D group.

Results: The mean BG level was higher in D compared with Na-D group $[136 \pm 22.9 \mathrm{mg} / \mathrm{dl}$ vs $118 \pm 21.5$ $\mathrm{mg} / \mathrm{dl}](p=0.009)$. Mean differences of $\triangle B G$ of $D$ (mean before and mean after) compared with $\triangle B G N a-$ $D$ (mean before and mean after) is $16.8 \mathrm{mg} / \mathrm{dl}(p=0.001)$. The mean of sprint speed is faster in the $D$ group [15.2 $\pm 1.25 \mathrm{sec}$ vs $15.9 \pm 1.61 \mathrm{sec}$ ] $(p=0.019)$, but we found no significant differences in $\mathrm{VO}_{2} \mathrm{max}$ between both groups $[42.1 \pm 3.44 \mathrm{ml} / \mathrm{min} / \mathrm{kg}$ vs $42.3 \pm 3.98 \mathrm{ml} / \mathrm{min} / \mathrm{kg}](p=0.834)$.

Conclusion: The present study demonstrated that D drink without added sodium has a large influence effect in increasing the BG level and sprint speed.

\section{Trial registration:}

ClinicalTrials, NCT04206579. Registered 20/12/2019 - Retrospectively registered, https://clinicaltrials.gov/ct2/show/NCT04206579?term=NCT04206579\&draw=2\&rank=1

\section{Background}

$\mathrm{CHO}$ solution can influence blood glucose response to exercise for thirty to forty five minutes (1). Maltodextrin $7.5 \%$ solution without sodium as a performance-enhancement purpose, can improve skilled and mind performance of the soccer players (2). Augmented glucose uptake due to the translocation of glucose transporter to the muscle membrane caused a temporary reduction in BG (3), making the BG decreased sharply in the starting period of a match (4). Fast decline in BG could bring bad effect to the skilled actions in a soccer match (5).

The cell needs glucose, and the permeation of glucose into it is affected with glucose transporter; the sodium-dependent glucose cotransporters (SGLTs) and the passive facilitative glucose transporters 
(GLUTs) (6). SGLT-1, serve as a main pathway of $\mathrm{CHO}$ absorption in the gut, in which absorption of glucose is bringing together with sodium-potassium ATPase (7) (8). SGLT-1 shows high affinity-low capacity with a saturation response (9). GLUT-2 will be expressed to the gut apical membrane in high glucose concentration (10). GLUT-2 shows low affinity-high capacity with no saturation response (9), which has greater absorption capacity than the SGLT-1 at high glucose concentration (9)

Delivery of the glucose is restricted by the transport capability of SGLT-1 (11).The gut has the capability to assimilate glucose through basal levels via SGLT1, but this capability gets to be constraining once dietary carbohydrate surpasses a certain level (12). The glucose oxidation rates peaks around $50-60 \mathrm{~g} / \mathrm{h}$ for each $60-70 \mathrm{~g}$ glucose consumed, and can not be increased anymore despite given $180 \mathrm{~g} / \mathrm{h}$ glucose (11). Since this confinement was not caused by gastric emptying, liver glycogen, and muscle glucose take-up, it was concluded that assimilation had to be limiting (13). When fructose was ingested in expansion of glucose, $\mathrm{CHO}$ oxidation rates were lifted over $60 \mathrm{~g} / \mathrm{h}(14)$, suggested that glucose assimilation across the gut apical membrane was the limiting factor and that the peak transport capability of SGLT-1 was reached (15).

Exposure to high intestinal luminal glucose $\geq 15 \mathrm{mM}(2.7 \mathrm{~g})$, or more modest glucose loads, induces GLUT-2 translocation (16) (17). The opening of Cav 1.3 Ca2+ channels following SGLT-1 depolarization of the apical membrane potential, will stimulate the enterocyte adenosine monophosphate kinase (AMP Kinase) that will induce GLUT-2 translocation (18).

The absorption of glucose can be amplified by apical GLUT-2 when the submucosal and enterocyte glucose concentration are lower than in the intestinal lumen (19). During in vitro analysis, following exposure of glucose, the time to reach a steady state of glucose aggregation inside the enterocytes is $\leq 2$ min (20) (21). When the gut luminal glucose is lower than the enterocyte concentration, it will ruin apical GLUT-2 for passive glucose assimilation, instead of accommodate net absorption (19) (22).

The distance coverage of soccer players during a match is $9-12 \mathrm{~km}$, of this, 8-12\% are sprinting (23). Soccer players require energy turnover from aerobic and anaerobic metabolism (24). A considerable oxidation of endogenous glucose stores is obvious in soccer competition (25). The advantageous results of $\mathrm{CHO}$ ingestion were related with the preservation of glycogen levels, which serve as an ergogenic effect, such as improved fuel substrate to the brain and muscle (26). As a result, the availability of glucose was appeared to impact soccer performance by improving the capacity to perform the intermittent bouts and may worsens the performance when the concentration is decreased (27).

Sports drinks are designed to supply $\mathrm{CHO}$, electrolytes and fluids to the body, which are absorbed swiftly from the gut. In other words, the period from ingestion until the $\mathrm{CHO}$, electrolytes and fluids reach the muscles and brain should be very short (28). Either 3\%-10\% glucose solution (29)(30) or $12 \%$ glucose with sodium added have the ergogenic effects (31). Commercial sports drinks generally contain both combination of $\mathrm{CHO}$ and sodium; To the best of our knowledge, there is no trial in which compares the differential effect of solely dextrose supplementation versus sodium dextrose in soccer players in terms 
of $\mathrm{BG}$ concentration, $\mathrm{VO}_{2}$ max and sprint speed, which may give a new paradigm for the available ergogenic sports drink. Therefore, we designed a randomized, double-blind trial in male soccer players to evaluate the effect of dextrose solution with zero sodium versus the solution of dextrose with $20 \mathrm{mM}$ sodium in terms of blood glucose, $\mathrm{VO}_{2} \mathrm{max}$, and sprint speed. The primary outcome was a mean difference in BG level between $\mathrm{D}$ and $\mathrm{Na}-\mathrm{D}$ intervention. Secondary outcomes were mean differences in $\mathrm{VO}_{2}$ max and sprint speed. We hypothesized that $\mathrm{D}$ supplementation, gives a superior effect than $\mathrm{Na}-\mathrm{D}$ supplementation in terms of blood glucose, $\mathrm{VO}_{2} \mathrm{max}$ and sprint speed.

\section{Methods}

\section{Study design and procedure}

This study was a randomized crossover (double-blind) design. Participants and researchers were blinded from the administered fluid type. Participants were randomly assigned to receive either dextrose (D) solution or sodium dextrose (Na-D) solution. Randomization took place immediately after the participants had been confirmed to be eligible for entering the study. The randomization code of the drink, was not made available to anyone involved in conducting or evaluating the study, and was released after the blind review and the freezing of the final database. After randomizing, the study was divided into three phases, as shown in Fig. 1. Assessment of health status, dietary intake, measurement of body composition, baseline blood glucose, baseline $\mathrm{VO}_{2}$ max, and baseline sprint speed were evaluated in phase I. In phase II, we measured the blood glucose before the participants drink the dextrose or sodium dextrose supplementation. We asked the participants to sprint before received the solution, then we record the time and calculating the $\mathrm{VO}_{2}$ max. After that, we give one type of solution (dextrose or sodium dextrose). In order to have a comparison of the post supplementation effect, the participants repeated the previously mentioned procedures in this phase II. Phase III was similar to phase II except for the nutritional supplementation. The participants could receive either dextrose or sodium dextrose in phase II, and the opposite alternative in phase III. This trial was conducted at UNM Banta-Bantaeng, Makassar, Indonesia, from April 2019 to May 2019.

\section{Supplement preparation}

The supplements consisted of dextrose (D) or sodium dextrose (Na-D). Glucose is a monosaccharide, which acts as an essential energy source through aerobic or anaerobic metabolism. Dextrose or Dglucose is an aldohexose stereoisomer of glucose. It is the most commonly occurring isomer of glucose in nature. Our pharmacist used $15 \mathrm{~g}$ of dextrose anhydrous to make a $150 \mathrm{ml}$ dextrose $10 \%$, with pH 5.27 . Another $150 \mathrm{ml}$ Sodium dextrose solution consisted of $10 \%$ dextrose, added with $20 \mathrm{mM}$ of sodium. The material is taken from Japan (Otsuka Holdings Co., Ltd.) and all of the entire mixing process was supervised by Akademis hospital licensed pharmacist.

\section{Participants}


Sample sizes for this research are twenty one, and it was calculated by equation $n=[\{(Z \grave{\alpha}+Z \square) X S d\} / d$ ]$^{2}$, with $Z \grave{\alpha}=1.96 ; Z \mathbb{Z}=0.842 ; S d=28.2 ; d=10$. Random allocation was performed using a random electronic generator via https://www.random.org/lists/. Our pharmacists staff were responsible to generate the random allocation sequence, enrolled participants, and assigned participants to interventions. After assignment of interventions, all of the participants and us, were blinded. A total of 50 male outfield academy soccer players were screened for the study. Thirty-two participants entered into the inclusion criteria. All were healthy and free of injury in the three months preceding the study. Three participants refused to join, and 6 were dropped out. Twenty-two participants participated (age, $19.6 \pm 1.1$ years; height, $165.7 \pm 5.25 \mathrm{~cm}$; weight, $52.5 \pm 8.47 \mathrm{~kg}$; body fat, $12.5 \pm 4.68 \%$; muscle mass, $82 \pm 4.7 \%$; BMR, $1346 \pm 147.0 \mathrm{kcal}$ ) in the study and were successfully analysed until the end. Prior to enrolling in the study, each participants's physical examination and health history were taken. Eligibility criteria were healthy men soccer players between 18 and 23 years of age, who exercised on average between 8 and 12 $\mathrm{h}$ per week the last month prior to inclusion. All participants were within the last meal four hours prior to the test. Exclusion criteria were the use of amylase supplement, suffering from fever and diarrhoea, using laxative agents within $24 \mathrm{~h}$, consuming $\mathrm{CHO}$ absorption inhibitors, caffeine, creatinine, beta alanine, sodium bicarbonate supplement within $24 \mathrm{~h}$, mean arterial pressure $<65 \mathrm{mmHg}$, knee or muscle injuries, history of diabetes mellitus and heart disease, going through the ketogenic diet program, history of gastrointestinal surgery, and total body fat percentages $>30 \%$. Participants who were currently taking any other dietary supplement, sports drink, or functional food intended to enhance performance or muscle mass, or had taken any of these in the previous week, were also excluded.

The study was approved by the Faculty of Medicine Hasanuddin University Research Ethics Committee with the reference number 214/UN4.6.4.5.31/PP36/2019. All research was performed in accordance with relevant regulations supervised under Hasanuddin University and department of sport science, Makassar State University. Written informed consent was obtained from all participants prior to inclusion.

\section{Intervention and procedures}

The participants were instructed to abstain from exercise $24 \mathrm{~h}$ prior to the testing in phase I, II and III, and they arrived at the field track by car, motorcycle or by public transportation. They were recommended to maintain usual eating pattern $48 \mathrm{~h}$ before the test and had a last meal 4 hours before the phase I. In addition, they were told to refrain from coffee and kind of sports drink $48 \mathrm{~h}$ prior to the test.

Dietary intake was collected using two days food recall. BG were measured from capillary blood glucose from the fingertip and immediately analysed (Aviva; Accucheck, Roche Diagnostics, Indiana, U.S.A), blood pressure was measured using aneroid sphygmomanometer (R1 shock-proof; Riester, Jungingen, Germany), heart rate was measured with wrist band pulse monitor (Bluetooth 4.0 wireless sport heart rate monitor WP290; Egoman, Shenzen, China), body weight, muscle, fat, water, metabolic rate was measured using the body composition analyzer (BC-545N; Tanita, Tokyo, Japan), body height was measured using a stadiometer (HR-200, Tanita, Tokyo, Japan), sprint speed were measured using a digital stopwatch (S23589 S23589P1; Seiko, Tokyo, Japan) 
Participants were instructed to refrain from strenuous physical activity in the 2 days preceding trial sessions and recorded all food consumed in the 2 days before the trial. Food records subsequently were analysed using professional German nutrition software (EBISpro, Nutrisurvey 2007). On arrival at the field, pre supplementation capillary blood samples were collected, and then all players run for 2x100 m and calculated the $\mathrm{VO}_{2}$ max using Uth-Sorenen-Overgaard-Pedersen formula and sprint speed was recorded. After doing the baseline measurement, each player waited for 15 minutes in order to consume either dextrose or sodium dextrose solution, and then waited for 15 minutes to have another subsequent capillary blood samples measurement. After that, the players run for $2 \times 100 \mathrm{~m}$, recorded the $\mathrm{VO}_{2} \mathrm{max}$ and sprint speed. The players remained in a rested state for 120 minutes as a crossover washed-out period, and then did the same protocol with a different solution.

\section{Statistics}

Descriptive statistics were used to characterize the participants (mean, standard deviation (SD), with 95\% confidence interval, and significance was accepted at $p<0.05$. Data were checked for normality as indicated by the Shapiro-Wilk test. Paired samples t tests were used for comparison before and after condition in blood sugar, $\mathrm{VO}_{2}$ max and sprint speed. All reported $\mathrm{p}$-values were based on two-sided tests. Exact values of $p<0.05$ were considered statistically significant. The data was analysed using IBM SPSS Statistics 25 for windows (SPSS Inc., Chicago, Illinois, USA). The sample size was selected based on an a priori power calculation. Accordingly, with a type I error of 0.05, power analysis revealed that for a 2-tailed paired data Student $t$ test a sample size of 21 individuals is adequate to achieve a power of $>80 \%$. To interpret the magnitude of effect, Cohen's $d$ effect sizes ( $\pm 95 \%$ confidence limits) were estimated using a purpose built spreadsheet, with effect size thresholds set at $<0.20,>0.50$, and $>0.80$ for small, moderate, large, effects respectively.

\section{Results}

Baseline characteristic for all 22 participants was shown in Table 1. All of the variables are within normal distribution. All of the participants $(n=22)$ completed the test without any injuries and none of the participants in both groups reported any kind of side effects. Due to the little differences in muscle ( $82 \pm$ $4.7 \%)$ and total body water percentages $(60.7 \pm 4.91 \%)$ of all participants, we used the similar dose of dextrose and sodium dextrose for all of the participants. 
Table 1

Baseline Characteristics of the study participants $(n=22)$

\section{Characteristic}

Age (years)

Height (cm)

Weight $(\mathrm{kg})$

Systolic blood pressure $(\mathrm{mmHg})$

Diastolic blood pressure $(\mathrm{mmHg})$

Body fat (\%)

Muscle mass (\%)

Bone mass $(\mathrm{kg})$

$\operatorname{BMR}(\mathrm{kcal})$

Visceral fat level

Total body water (\%)

Blood Glucose $(\mathrm{mg} / \mathrm{dl})$

VO2 $\max (\mathrm{ml} / \mathrm{min} / \mathrm{kg})$

Sprint speed (sec)

Heart rate (times/minute)

Protein Intake $(\mathrm{g})^{1}$

Carbohydrate Intake $(g)^{1}$

Fat intake $(\mathrm{g})^{1}$

Energy intake $(\mathrm{kcal})^{1}$

\section{Mean \pm SD}

$19.6 \pm 1.12$

$165.7 \pm 5.25$

$52.7 \pm 8.47$

$109 \pm 5.4$

$79 \pm 9.5$

$12.5 \pm 4.68$

$82 \pm 4.7$

$2.5 \pm 0.31$

$1346 \pm 147.0$

$2.9 \pm 1.0$

$60.7 \pm 4.91$

$93 \pm 2.5$

$41.0 \pm 3.21$

$16.13 \pm 1.333$

$60 \pm 4.1$

$98.4 \pm 16.23$

$327.4 \pm 41.28$

$48.1 \pm 14.68$

$2137 \pm 295.8$

Data are presented as mean \pm standard deviation (SD) unless otherwise stated; ${ }^{1}$ Average of $48 \mathrm{~h}$ food recall

The effect of dextrose or sodium dextrose supplementation on blood glucose, $\mathrm{VO}_{2}$ max and sprint are presented in Figs. 2, 3 and 4 respectively. The mean of blood glucose before and after dextrose supplementation are $91 \pm 11.6 \mathrm{mg} / \mathrm{dl}$ and $136 \pm 22.9 \mathrm{mg} / \mathrm{dl}$. The mean of blood glucose before and after sodium dextrose supplementation are $91 \pm 9.1 \mathrm{mg} / \mathrm{dl}$ and $118 \pm 21.5 \mathrm{mg} / \mathrm{dl}$. Dextrose supplementation had a higher blood glucose level than sodium dextrose $(136 \mathrm{mg} / \mathrm{dl}$ versus $118 \mathrm{mg} / \mathrm{dl})$. This data was also supported by the mean differences of BG before dextrose supplementation compared with before sodium dextrose was $0.4 \pm 5.86 \mathrm{mg} / \mathrm{dl}, p=0.747$ (95\% Cl -2.19, 3.01), which means their differences was 
not statisctically significant. The data between dextrose and sodium dextrose group was shown in Table 2 and 3. Another corroboration of the data, was found that the mean differences of BG after dextrose supplementation compared with after sodium dextrose was $17 \pm 28.2 \mathrm{mg} / \mathrm{dl}, p=0.009(95 \% \mathrm{Cl} 4.7-$ 29.8). Cohen's d effect's size $=0.60$. However, to sum it all, the primary endpoint is to know the mean differences of $\triangle B G$ in the dextrose group (before and after supplementation) compared with a $\triangle B G$ sodium dextrose group (before and after supplementation) as shown in Table 3, which has the $p$-value of 0.011 and effect's sizes 0.6.

Table 2

Before and after administration of dextrose and sodium dextrose

\begin{tabular}{|c|c|c|c|c|c|c|c|c|}
\hline & \multicolumn{4}{|c|}{ Dextrose } & \multicolumn{4}{|c|}{$\begin{array}{l}\text { Sodium } \\
\text { dextrose }\end{array}$} \\
\hline & \multicolumn{4}{|l|}{$\mathrm{n}=22$} & \multicolumn{4}{|l|}{$\mathrm{n}=22$} \\
\hline & Before & \multicolumn{3}{|l|}{ After } & Before & \multicolumn{3}{|l|}{ After } \\
\hline & $\begin{array}{l}\text { Mean } \pm \\
\text { SD }\end{array}$ & $\begin{array}{l}\text { Mean } \\
\pm \text { SD }\end{array}$ & $\begin{array}{l}p- \\
\text { value }\end{array}$ & $\begin{array}{l}\text { Cohen's d } \\
\text { effect sizes }\end{array}$ & $\begin{array}{l}\text { Mean } \pm \\
\text { SD }\end{array}$ & $\begin{array}{l}\text { Mean } \\
\pm S D\end{array}$ & $\begin{array}{l}p- \\
\text { value }\end{array}$ & $\begin{array}{l}\text { Cohen's } \\
\text { d effect } \\
\text { sizes }\end{array}$ \\
\hline $\begin{array}{l}\mathrm{BG} \\
(\mathrm{mg} / \mathrm{dl})\end{array}$ & $\begin{array}{l}91.4 \pm \\
11.62\end{array}$ & $\begin{array}{l}136.0 \\
\pm \\
22.91\end{array}$ & 0.001 & 3.02 & $\begin{array}{l}91.0 \pm \\
9.18\end{array}$ & $\begin{array}{l}118.7 \\
\pm \\
21.53\end{array}$ & 0.001 & 1.29 \\
\hline $\begin{array}{l}\text { Sprint } \\
\text { (sec) }\end{array}$ & $\begin{array}{l}14.69 \pm \\
1.330\end{array}$ & $\begin{array}{l}15.26 \\
\pm \\
1.258\end{array}$ & 0.012 & 0.59 & $\begin{array}{l}14.61 \pm \\
1.468\end{array}$ & $\begin{array}{l}15.90 \\
\pm \\
1.612\end{array}$ & 0.001 & 1.23 \\
\hline $\mathrm{VO}_{2} \max$ & $\begin{array}{l}42.7 \pm \\
3.69\end{array}$ & $\begin{array}{l}42.1 \pm \\
3.44\end{array}$ & 0.282 & 0.23 & $\begin{array}{l}42.5 \pm \\
3.98\end{array}$ & $\begin{array}{l}42.3 \\
\pm 3.99\end{array}$ & 0.219 & 0.27 \\
\hline $\begin{array}{l}\text { HR } \\
(\mathrm{bpm})^{1}\end{array}$ & $\begin{array}{l}148 \pm \\
3.04\end{array}$ & $\begin{array}{l}149 \pm \\
3.26\end{array}$ & 0.204 & 0.27 & $\begin{array}{l}148 \pm \\
2.78\end{array}$ & $\begin{array}{l}148 \pm \\
3.41\end{array}$ & 0.590 & 0.11 \\
\hline \multicolumn{9}{|c|}{$\begin{array}{l}\text { Data are presented as mean values } \pm \text { standard deviations }(\mathrm{SD}) \text {. The } \mathrm{P} \text {-value represents the } \\
\text { significance level of the difference between the before dextrose or sodium dextrose and after the } \\
\text { dextrose or sodium dextrose supplementation. Cohen's d represents the effect sizes of the p-value. } \\
\text { BG, blood glucose; } \mathrm{VO}_{2} \text { max, maximal oxygen uptake; HR, heart rate; BPM, beat per minute. }{ }^{1} \text { Measured } \\
\text { at the end of the sprint sessions. }\end{array}$} \\
\hline
\end{tabular}


Table 3

Differences of blood glucose, sprint and $\mathrm{VO}_{2}$ max before and after dextrose or sodium dextrose supplementation.

\begin{tabular}{|c|c|c|c|c|c|c|}
\hline \multirow{3}{*}{ 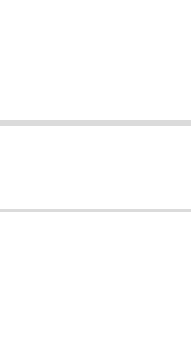 } & \multirow{2}{*}{$\begin{array}{l}\text { Dextrose } \\
n=22\end{array}$} & \multirow{2}{*}{$\begin{array}{l}\begin{array}{l}\text { Sodium } \\
\text { Dextrose }\end{array} \\
\mathrm{n}=22\end{array}$} & \multicolumn{4}{|c|}{ Diff. Dextrose versus Sodium Dextrose } \\
\hline & & & & & & \\
\hline & $\begin{array}{l}\text { Mean diff } \pm \\
S D\end{array}$ & Mean $_{\text {diff }} \pm S D$ & $\begin{array}{l}\text { Mean } \\
\text { diff }\end{array}$ & $95 \% \mathrm{Cl}$ & $\begin{array}{l}\mathrm{p}- \\
\text { value }\end{array}$ & $\begin{array}{l}\text { Cohen's d effect } \\
\text { sizes }\end{array}$ \\
\hline $\begin{array}{l}\mathrm{BG} \\
(\mathrm{mg} / \mathrm{dl})\end{array}$ & $\begin{array}{l}-44.5 \pm \\
14.76\end{array}$ & $-27.7 \pm 21.33$ & 16.8 & $\begin{array}{l}4.27 \\
29.44\end{array}$ & 0.011 & 0.6 \\
\hline $\begin{array}{l}\text { Sprint } \\
\text { (sec) }\end{array}$ & $\begin{array}{l}-0.57 \pm \\
0.966\end{array}$ & $-1.28 \pm 1.035$ & -0.71 & $\begin{array}{l}-1.24 \\
-0.18\end{array}$ & 0.011 & 0.6 \\
\hline $\mathrm{VO}_{2} \max$ & $0.5 \pm 2.46$ & $0.1 \pm 0.65$ & -0.40 & $\begin{array}{l}-1.64 \\
0,83\end{array}$ & 0.507 & 0.1 \\
\hline
\end{tabular}

The mean of $\mathrm{VO}_{2} \mathrm{max}$ before and after dextrose supplementation are $42.7 \pm 3.69 \mathrm{ml} / \mathrm{min} / \mathrm{kg}$ and $42.1 \pm$ $3.44 \mathrm{ml} / \mathrm{min} / \mathrm{kg}$ as shown in Fig. 3. The mean of $\mathrm{VO}_{2}$ max before and after sodium dextrose supplementation are $42.5 \pm 3.98 \mathrm{ml} / \mathrm{min} / \mathrm{kg}$ and $42.3 \pm 3.99 \mathrm{ml} / \mathrm{min} / \mathrm{kg}$. The mean differences of $\mathrm{VO}_{2} \mathrm{max}$ before dextrose supplementation compared with before sodium dextrose was $0.2 \pm 4.57 \mathrm{ml} / \mathrm{min} / \mathrm{kg}, p=$ $0.810(95 \% \mathrm{Cl}-1.79,2.26)$. The mean differences of $\mathrm{VO}_{2} \mathrm{max}$ after dextrose supplementation compared with after sodium dextrose was $-0.16 \pm 3.65 \mathrm{ml} / \mathrm{min} / \mathrm{kg}, p=0.834(95 \% \mathrm{Cl}-1.78,1.45)$. Cohen's d effect's size $=0.04$. The secondary endpoint is to know the mean differences of the $\Delta \mathrm{VO}_{2}$ max dextrose group (before and after supplementation) compared with a $\Delta \mathrm{VO}_{2}$ max sodium dextrose group (before and after supplementation), as shown in Table 3 , which has a $p$-value of 0.507 and effect's sizes 0.1 , as shown in Table 3.

The mean of sprint speed before and after dextrose supplementation is $14.6 \pm 1.33 \mathrm{sec}$ and $15.2 \pm 1.25$ sec. The mean of sprint speed before and after sodium dextrose supplementation is $14.6 \pm 1.46 \mathrm{sec}$ and $15.9 \pm 1.61 \mathrm{sec}$. The mean differences of sprint speed before dextrose supplementation compared with before sodium dextrose were $0.07 \pm 0.724 \mathrm{sec}, p=0.640$ ( $95 \% \mathrm{Cl}-0.24,0.39)$. The mean differences of sprint speed after dextrose supplementation compared with after sodium dextrose was - $0.64 \pm 1.184$ sec, $p=0.019(95 \% \mathrm{Cl}-1.16,-0.11)$. Cohen's d effect's size $=0.55$. The mean of sprint speed is faster in a dextrose supplementation group than the sodium dextrose group (15.2 sec versus $15.9 \mathrm{sec}$ ). This value was supported by the secondary endpoint of this study. The mean differences of $\Delta$ sprint speed in the dextrose group (before and after supplementation) compared with the $\Delta$ sprint speed in sodium dextrose group (before and after supplementation) as shown in Table 3, which has a $p$-value of 0.011 and effect's sizes 0.6 , as shown in Table 3. 


\section{Discussion}

We examined the effect of dextrose versus sodium dextrose supplementation on $\mathrm{BG}, \mathrm{VO}_{2}$ max and sprint speed of the young male soccer players. The main finding was that supplementation with dextrose had a better ergogenic effect than sodium dextrose in terms of BG and sprint speed, but still could not improve the $\mathrm{VO}_{2}$ max.

Soccer is an intermittent, high-intensity team sport in adult players. Muscle glycogen in certain muscle fibres and BG used to drop to levels that may damage cognitive function (32). As a result, soccer players are often advised to consume the $\mathrm{CHO}$ solution during competitions to supply muscle glycogen reservations and maintain $\mathrm{BG}$ concentrations during the match (5). The effect of $\mathrm{CHO}$ solution on energy metabolism to actual soccer matches has been widely known (1). BG levels can be maintained optimally until the end of the game if the players consumed exogenous $\mathrm{CHO}$ (33). Consumption of $\mathrm{CHO}$ is a nutritional strategy that is usually recommended for soccer players, that aim to maintain endogenous energy stores, and prevent excessive physical and cognitive performance decline throughout the match (5).

Consumption of $\mathrm{CHO}$ has been proven to improve the performance index of expertise in playing soccer, where the reduction in BG levels can negatively influence the skilled actions involved (34). Considering the performance benefits of $\mathrm{CHO}$ supplementation which is able to reduce glycogen 'depletion' levels throughout the game, it is recommended that soccer players consume $30-60 \mathrm{~g} / \mathrm{h}$ of exogenous $\mathrm{CHO}$ supplementation during competitions to maintain the BG level and glycogen reserves (35). However, the superior effect on the rate of increase in BG of pure ergogenic dextrose supplementation compared with sodium dextrose have not yet been known, therefore started from that point this study was conducted.

We obtained the results of the mean differences of BG after dextrose versus after sodium dextrose group was $136 \pm 22.9 \mathrm{mg} / \mathrm{dl}$ and $118 \pm 21.5 \mathrm{mg} / \mathrm{dl}$. This positive finding may suggest the mechanism that solely dextrose supplementation via a GLUT-2 pathway was able to transport CHO into the plasma faster than SGLT-1 pathway. CHO can be moved through the apical membrane of enterocytes via a GLUT-2 pathway (22), which may occur if the $\mathrm{CHO}$ supplementation is given without sodium as a co-transporter, evading the SGLT-1 pathway (36).

In soccer players, an increase in BG levels can be observed from 75 min onwards when a $10 \% \mathrm{CHO}$ electrolyte solution is consumed before and during soccer matches, compared to a placebo-fluidelectrolyte control (37).

The total $\mathrm{CHO}$ concentration in sports drinks is $4-8 \%$ and the sodium content is $10-25 \mathrm{mM}(38)$. In this study, we were using a higher $\mathrm{CHO}$ concentration of $10 \%$ with $20 \mathrm{mM}$ sodium. This condition can explain that at a higher $\mathrm{CHO}$ concentration will trigger absorption through the GLUT 2 pathway, possibly without going through the SGLT 1 route. It is also known that the apical GLUT-2 absorption component is greater than the SGLT-1 at high luminal glucose concentrations (39) (40). Apical GLUT-2 is tightly regulated by long and short-term $\mathrm{CHO}$ supply and also by local and endocrine hormones, disease (diabetes mellitus), 
cellular energy level, and the regulation occurs through intracellular signalling pathways (9). Thus, apical GLUT-2 can act as the main pathway for sugar absorption. Apical GLUT-2 acts a guard mechanism by preventing high concentrations of $\mathrm{CHO}$ escape into the large intestine (41).

Intestinal CHO absorption consists of SGLT and GLUT types. Activation of GLUT2 in the apical gut membrane increase with glucose concentration (9). and the diffusive component. Evidence shows that the diffusion part is mediated by the translocation of transient GLUT-2 from the intracellular enterocyte vesicles into the apical membrane, especially after high luminal glucose, which allow bulk absorption of glucose (42) (43). The apical GLUT-2 pathway from luminal sugar uptake could be inserted within minutes into the apical of enterocytes in response to high glucose level during food assimilation (16). As in physiologic condition, after a meal, glucose level in the gut lumen rises, which could saturate the SGLT1. The GLUT-2 pathway in the apical membrane, then facilitate $\mathrm{CHO}$ diffusion down the concentration gradient. This study was given supplementation of $150 \mathrm{cc}$ of dextrose $10 \%$, equivalent to 15 grams of dextrose.

The slower mean increment of BG in the administration of sodium dextrose solution can be partly explained by the fact that SGLT-1 is a rate limiting pathway for enterocyte glucose absorption. SGLT-1 uses a transmembrane sodium gradient to carry out the cellular uptake (44). Such a situation may occur slower, considering the condition of soccer players is not in the actual match condition (45), suggesting lesser sodium loss through sweat perspiration that may give a result in a weaker sodium transmembrane gradient (46)(47). Also, one main rule when using sport drinks that contain dextrose and sodium, is that they should not be diluted. This would change the concentrations of $\mathrm{CHO}$ and sodium. Both will affect the speed at which the drink empties from the stomach, so the whole mechanism of energy and fluid delivery will be delayed. The benefits of using sports drinks are proven only for adults involved in rigorous exercise, and doing training at hot condition and high humidity (28).

$\mathrm{VO}_{2}$ max differences between groups given dextrose compared with sodium dextrose were not significant. Soccer is predominantly intermittent aerobic sport interspersed with periods of high-intensity anaerobic, which may perform different types of exercise intensities and using the aerobic and anaerobic energy systems. Total duration of active play in soccer is $\pm 95 \mathrm{~min}$, suggested the main energy source during the match is supplied through aerobic glycolysis. The average $\mathrm{VO}_{2}$ max during match play was reported to be around $75-80 \%$. The mean and peak heart rate of players was estimated to be around 85 and $98 \%$ respectively. Nonetheless, $\mathrm{VO}_{2}$ max values of soccer players were shown to vary noticeably, with current high level soccer players are suggested to acquire maximal oxygen uptakes between $60-70 \mathrm{ml} / \mathrm{kg} / \mathrm{min}$, with an estimated minimum of $65 \mathrm{ml} / \mathrm{kg} / \mathrm{min}$ in elite soccer players (27).

People with high fitness (as measured by $\mathrm{VO}_{2} \mathrm{max}$ ) are more physically active in their daily life than those with low fitness. $\mathrm{VO}_{2}$ max is a modifiable variable and it can be increased through exercise. High intensity interval resting training was found to improve $\mathrm{VO}_{2}$ max more effectively than moderate continuous session (48). We found no differences between the two groups because it has been known that $\mathrm{VO}_{2} \mathrm{max}$ is not only influenced by BG levels, but also by other factors, such as cardiorespiratory fitness (49). 
However, to determine if a dose-response relationship exists between exercise intensity and traininginduced increases in $\mathrm{VO}_{2} \mathrm{max}$, result from meta-analysis suggests that exercise training intensity has no effect on the elevation of training-induced $\mathrm{VO}_{2} \max$, but similar adaptations can be achieved in low training doses at higher exercise intensities than higher training doses of lower intensity (50). $\mathrm{VO}_{2}$ max is a measurement of the maximum capacity to utilize oxygen in multilevel exercise tests, and act as a measure of the cardiorespiratory fitness system in soccer players. The cardiovascular and thermoregulatory systems are first affected by low hydration, especially when exercise is performed in the high temperature or high humidity conditions (28), but in this experiment design, the players were not performed in the heat environment.

During soccer training sessions, 6-7\% $\mathrm{CHO}$ solutions have succeeded in increasing the sprint speed (33). Glycogen breakdown declines with a simultaneous elevation in extra-muscular BG levels, to maintain normal BG during the match (27). CHO supplementation improved intermittent running, soccer skill performance, the distance covered during the game and were correlated with the maintenance of glycogen levels when compared to a placebo beverage (27). The faster sprint speed in the dextrose group might be explained by the effect of the faster increment in BG mean in the dextrose group, served as a readily available substrate to fuel the muscle glycogen. $\mathrm{CHO}$ concentration in the sports drinks range in between 4-8\% and the sodium content are between 10-25 mM (38), but in this study, we used a higher $\mathrm{CHO}$ concentration reached the $10 \%$ with $20 \mathrm{mM}$ sodium. This fact may explain that at higher $\mathrm{CHO}$ concentrations, it will trigger absorption through the GLUT 2 pathway without going through the SGLT 1 . Half-time for apical GLUT 2 membrane insertion was very rapid ( $3.5 \mathrm{~min})$ and correlated with activation of the protein kinase C $\beta$ II isoform. The transient presence of GLUT 2 in the apical enterocyte has been proved using antibodies to epitopes within $\mathrm{N}$-terminal regions. Its location in the apical membrane has been confirmed by cell immunofluorescence imaging using extracellular loop antibody. GLUT 2 can transport glucose and has a very high Kt (transport constant) for glucose, indicate that apical GLUT 2 has the role for the diffusive component of glucose absorption, which at high glucose levels, the GLUT2 component accounted for $\pm 75 \%$ of the absorption (16). In animal model, when the glucose concentration is higher in the intestinal gut lumen than in plasma, rapid trafficking of GLUT2 to the apical membrane occurs in enterocytes, accounts for the facilitated glucose absorption (51). With BG level rising faster in the dextrose group, it will provide the added benefit of a faster sprint speed. The possible underlying mechanism was because of the increased availability of substrates which can be used as a rapid fuel for muscle contraction (14). However, the limitation of our study is the research was not performed under real soccer match.

\section{Conclusions}

Our study indicated that solely dextrose supplementation effectively supports blood sugar and sprint speed in soccer players. A solution of $150 \mathrm{ml}$ dextrose $10 \%$ elevated blood glucose faster than sodium dextrose solution. On the basis of our results, we conclude that with regard to the beginning of the soccer match, a $10 \%$ of dextrose solution ingested 15 minutes before the match, could elevate BG faster and

Page $12 / 21$ 
may have a good impact in sprint velocity, as in the beginning of a match, to kick off and dominate it. These findings suggest a future suggestion to re-evaluate the energy drink which nearly always has a mixture of $\mathrm{CHO}$ and electrolyte.

\section{Abbreviations}

BG: Blood glucose; $\mathrm{CHO}$ : Carbohydrate; D:Dextrose; HR: Heart rate; $\mathrm{Na}-\mathrm{D}$ : Sodium dextrose; $\mathrm{VO}_{2} \mathrm{max}$ : Maximal oxygen uptake;

\section{Declarations}

\section{Acknowledgements:}

This research is partially funded by the Indonesian Ministry of Research, Technology and Higher Education under WCU program managed by Institut Teknologi Bandung.

\section{Author Contributions:}

A.B, S.A and N.T designed the review and completed the major parts of the article. A.B, MT, I.Y.C and F.A.P were all responsible for compiling and reviewing the articles. M.T, I.Y.C, and F.A.P were responsible for field procedures. A.B and I.Y.C created the artwork. All authors read and approved this final article.

\section{Conflicts of Interest:}

The authors declare no conflict of interest in the areas of financial, institutional, and/or personal relationships that might inappropriately influence our actions or statements.

\section{Ethics approval and consent to participate:}

The study was approved by the Faculty of Medicine Hasanuddin University Research Ethics Committee with the reference number 214/UN4.6.4.5.31/PP36/2019. Written informed consent was obtained from all participants prior to inclusion.

\section{Consent for publication:}

This manuscripts containing no individual person's data in any form (including individual details, images or videos). All of the participants has fully consent to us in order to publish this research material for scientific purpose. 


\section{Availability of data and material:}

Availability of Data and Materials are provided in the supplementary materials in xlsx format.

\section{Funding}

Major part of our research has been funded with our own money, and we also had another additional funded by the Indonesian Ministry of Research, Technology and Higher Education under WCU program managed by Institut Teknologi Bandung

\section{References}

1. blood glucose and lactate concentrations. J Athl Train. 2014;49(4):447-53.

2. Currell $K$, Conway $S$, Jeukendrup AE. Carbohydrate ingestion improves performance of a new reliable test of soccer performance. Int J Sport Nutr Exerc Metab. 2009;19(1):34-46.

3. Bangsbo J, laia FM, Krustrup P. Metabolic Response and Fatigue. Int J Sports Physiol Perform. 2007; (2):111-27.

4. Russell M, Rees $G$, Benton $D$, Kingsley M. An exercise protocol that replicates soccer match-play. Int J Sports Med. 2011;32(7):511-8.

5. Hills SP, Russell M. Carbohydrates for soccer: A focus on skilled actions and half-time practices. Nutrients. 2018;10(1).

6. Navale AM, Paranjape AN. Glucose transporters: physiological and pathological roles. Biophys Rev. 2016;8(1):5-9.

7. Dobbins RL, Greenway FL, Chen L, Liu Y, Breed SL, Andrews SM, et al. Selective sodium-dependent glucose transporter 1 inhibitors block glucose absorption and impair glucose-dependent insulinotropic peptide release. Am J Physiol - Gastrointest Liver Physiol. 2015;308(11):G946-54.

8. Erokhova L, Horner A, Ollinger N, Siligan C, Pohl P. The sodium glucose cotransporter SGLT1 is an extremely efficient facilitator of passive water transport. J Biol Chem. 2016;291(18):9712-20.

9. Kellett GL, Brot-Laroche E. Apical GLUT2: A major pathway of intestinal sugar absorption. Diabetes. 2005;54(10):3056-62.

10. Kellett GL. The facilitated component of intestinal glucose absorption. J Physiol. 2001;531(3):58595.

11. Jeukendrup A. A step towards personalized sports nutrition: Carbohydrate intake during exercise. Sport Med. 2014;44(SUPPL.1).

12. Jeukendrup AE. Training the Gut for Athletes. Sport Med. 2017;47(s1):101-10.

13. Achten J, Halson SL, Moseley L, Rayson MP, Casey A, Jeukendrup AE. Higher dietary carbohydrate content during intensified running training results in better maintenance of performance and mood state. J Appl Physiol. 2004;96(4):1331-40. 
14. Jentjens RLPG, Achten J, Jeukendrup AE. High oxidation rates from combined carbohyrates ingested during exercise. Med Sci Sports Exerc. 2004;36(9):1551-8.

15. Stellingwerff T, Pfeeffer B, Stellingwerff T, Zaltas E, Jeukendrup AE. Oxidation of Solid versus Liquid $\mathrm{CHO}$ Sources during Exercise Oxidation of Solid versus Liquid CHO Sources during Exercise. 2015; (NOVEMBER 2010):2030-8.

16. Kellett GL, Brot-Laroche E, Mace OJ, Leturque A. Sugar Absorption in the Intestine: The Role of GLUT2. Annu Rev Nutr. 2008;28(1):35-54.

17. Mace OJ, Affleck J, Patel N, Kellett GL. Sweet taste receptors in rat small intestine stimulate glucose absorption through apical GLUT2. J Physiol. 2007;582(1):379-92.

18. Mace OJ, Morgan EL, Affleck JA, Lister N, Kellett GL. Calcium absorption by Cav1.3 induces terminal web myosin II phosphorylation and apical GLUT2 insertion in rat intestine. J Physiol. 2007;580(2):605-16.

19. Naftalin RJ. A computer model simulating human glucose absorption and metabolism in health and metabolic disease states. F1000Research. 2016;5(0):1-37.

20. Kimmich GA, Randles J. Sodium-sugar coupling stoichiometry in chick intestinal cells. Am J Physiol. 1984;247(1 Pt 1):74-82.

21. MacLeod RJ, Hamilton JR. Volume regulation initiated by $\mathrm{Na}+$-nutrient cotransport in isolated mammalian villus enterocytes. Am J Physiol - Gastrointest Liver Physiol. 1991;260(1 23-1).

22. Naftalin RJ. Does apical membrane GLUT2 have a role in intestinal glucose uptake? F1000Research. 2014;3:1-33.

23. Gabbett TJ, Mulvey MJ. Time-motion analysis of small-sided training games and competition in elite women soccer players. J Strength Cond Res. 2008;22(2):543-52.

24. Bangsbo J, Mohr M, Krustrup P, Bangsbo J, Mohr M, Krustrup P. Physical and metabolic demands of training and match-play in the elite football player. J Sports Sci. 2006;24(7):665-74.

25. Alghannam AF. Metabolic limitations of performance and fatigue in football. Asian J Sports Med. 2012;3(2):65-73.

26. Hearris MA, Hammond KM, Fell JM, Morton JP. Regulation of Muscle Glycogen Metabolism during Exercise: Implications for Endurance Performance and Training Adaptations. Nutrients. 2018;10(3):1-21.

27. F Alghannam A. Physiology of Soccer: The Role of Nutrition in Performance. J Nov Physiother. 2013;

28. Simulescu V, llia G, Macarie L, Merghes P. Sport and energy drinks consumption before, during and after training. Sci Sport [Internet]. 2019;34(1):3-9. Available from: https://doi.org/10.1016/j.scispo.2018.10.002

29. Vandenbogaerde TJ, Hopkins WG. Effects of acute carbohydrate supplementation on endurance performance: A meta-analysis. Sport Med. 2011;41(9):773-92.

30. Cermak NM, Loon LJC Van. The Use of Carbohydrates During Exercise as an Ergogenic Aid. Sport Med. 2013;43:1139-55. 
31. Harper ALD, Stevenson EJ, Rollo I, Russell M. The influence of a 12 per cent carbohydrate-electrolyte beverage on self-paced soccer-specific exercise performance. J Sci Med Sport [Internet]. 2017; Available from: http://dx.doi.org/10.1016/j.jsams.2017.04.015

32. Russell $M$, Kingsley $M$. The efficacy of acute nutritional interventions on soccer skill performance. Sport Med. 2014;44(7):957-70.

33. Baker LB, Rollo I, Stein KW, Jeukendrup AE. Acute effects of carbohydrate supplementation on intermittent sports performance. Vol. 7, Nutrients. 2015. 5733-5763 p.

34. Russell M, Benton D, Kingsley M. Influence of carbohydrate supplementation on skill performance during a soccer match simulation. J Sci Med Sport [Internet]. 2012;15(4):348-54. Available from: http://dx.doi.org/10.1016/j.jsams.2011.12.006

35. Thomas DT, Erdman KA, Burke LM. American College of Sports Medicine Joint Position Statement. Nutrition and Athletic Performance. Med Sci Sport Exerc [Internet]. 2016;48(3):543-68. Available from: https://www.ncbi.nlm.nih.gov/pubmed/26891166

36. Afshar N, Safaei S, Nickerson DP, Hunter PJ, Suresh V. Computational Modeling of Glucose Uptake in the Enterocyte. Front Physiol. 2019;10(APR):1-12.

37. Kingsley M, Penas-Ruiz C, Terry C, Russell M. Effects of carbohydrate-hydration strategies on glucose metabolism, sprint performance and hydration during a soccer match simulation in recreational players. J Sci Med Sport [Internet]. 2014;17(2):239-43. Available from: http://dx.doi.org/10.1016/j.jsams.2013.04.010

38. Burke LM, Meyer NL, Pearce J. National nutritional programs for the 2012 London Olympic Games: A systematic approach by three different countries. Nestle Nutr Inst Workshop Ser. 2013;76:103-20.

39. Schreck K, Melzig MF. Intestinal saturated long-chain fatty acid, glucose and fructose transporters and their inhibition by natural plant extracts in caco-2 cells. Molecules. 2018;23(10):1-30.

40. Röder P V., Geillinger KE, Zietek TS, Thorens B, Koepsell H, Daniel H. The role of SGLT1 and GLUT2 in intestinal glucose transport and sensing. PLoS One. 2014;9(2):20-2.

41. Kellett GL. Perspectives in diabetes. J Natl Med Assoc. 2005;54(October):3056-62.

42. Chaudhry RM, Scow JS, Madhavan S, Duenes JA, Sarr MG. Acute Enterocyte Adaptation to Luminal Glucose: A Posttranslational Mechanism for Rapid Apical Recruitment of the Transporter GLUT2. J Gastrointest Surg. 2012;16(2):312-9.

43. Scow JS, Tavakkolizadeh A, Zheng Y, Sarr MG. Acute "adaptation" by the small intestinal enterocyte: A posttranscriptional mechanism involving apical translocation of nutrient transporters. Surgery [Internet]. 2011;149(5):601-5. Available from: http://dx.doi.org/10.1016/j.surg.2011.02.001

44. Seidelmann SB, Feofanova E, Yu B, Franceschini N, Claggett B, Kuokkanen M, et al. Genetic Variants in SGLT1, Glucose Tolerance, and Cardiometabolic Risk. J Am Coll Cardiol. 2018;72(15):1763-73.

45. Godek SF, Peduzzi C, Burkholder R, Condon S, Dorshimer G, Bartolozzi AR. Sweat rates, sweat sodium concentrations, and sodium losses in 3 groups of professional football players. J Athl Train. 2010;45(4):364-71. 
46. Baker LB. Sweating Rate and Sweat Sodium Concentration in Athletes: A Review of Methodology and Intra/Interindividual Variability. Sport Med. 2017;47(s1):111-28.

47. Thorsen $K$, Drengstig T, Ruoff P. Transepithelial glucose transport and $\mathrm{Na}^{+} / \mathrm{K}^{+}$homeostasis in enterocytes: An integrative model. Am J Physiol - Cell Physiol. 2014;307(4):320-37.

48. Zisko N, Stensvold D, Hordnes-Slagsvold K, Rognmo Ø, Nauman J, Wisløff U, et al. Effect of Change in VO2max on Daily Total Energy Expenditure in a Cohort of Norwegian Men: A Randomized Pilot Study. Open Cardiovasc Med J. 2015;9(1):50-7.

49. Amman M (V AMC. Pulmonary system limitations to endurance exercise performance in humans. Exp Physiol. 2012;97(3):311-8.

50. Trisha S (School of K. The Effect of Training Intensity on VO2max in Young Healthy Adults: A MetaRegression and Meta-Analysis. Int J Exerc Sci. 2016;9(2):230-47.

51. Thazhath SS, Wu T, Young RL, Horowitz M, Rayner CK. Glucose absorption in small intestinal diseases. Expert Rev Gastroenterol Hepatol. 2014;8(3):301-12.

\section{Figures}




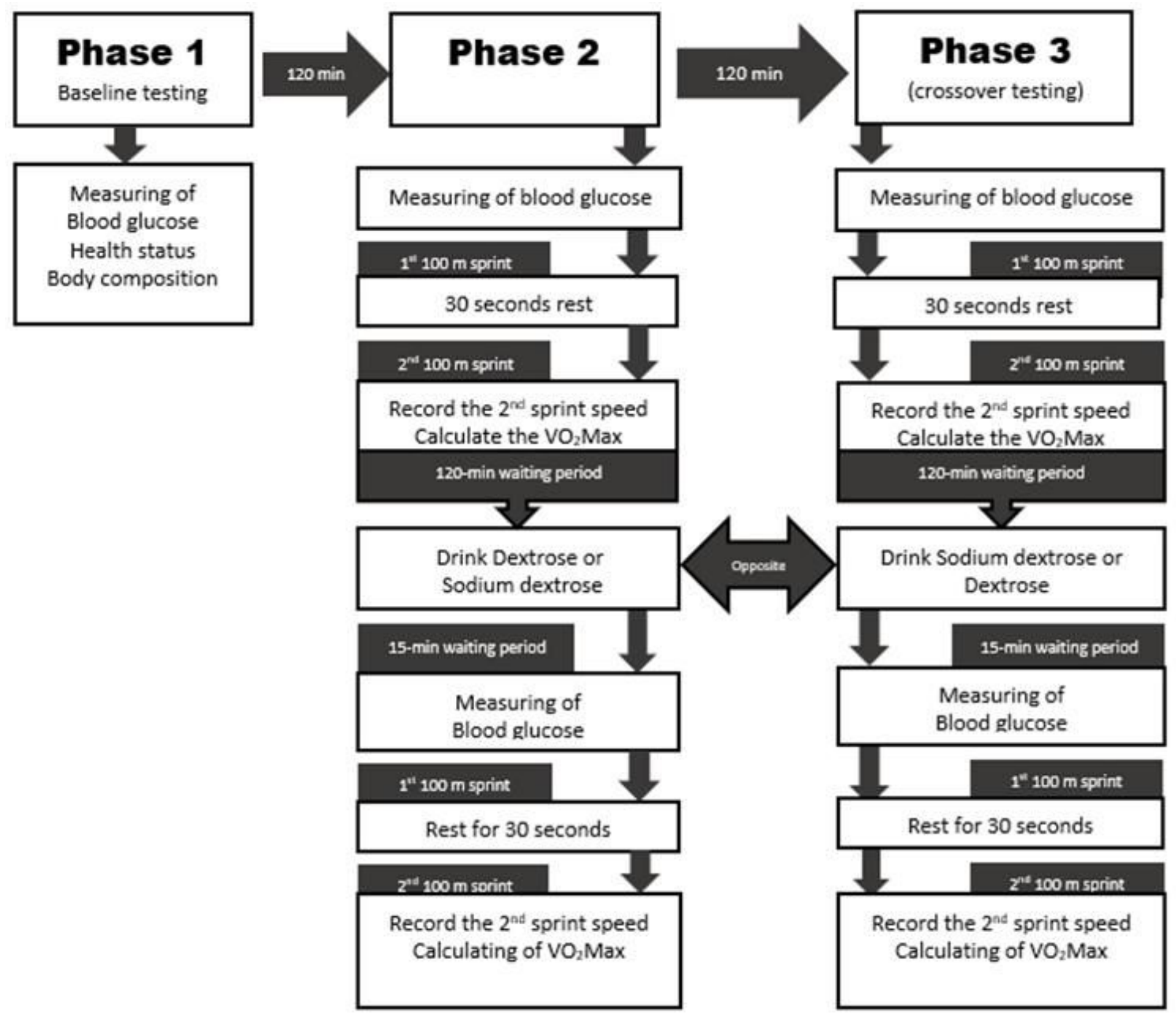

Figure 1

Flowchart of the study 


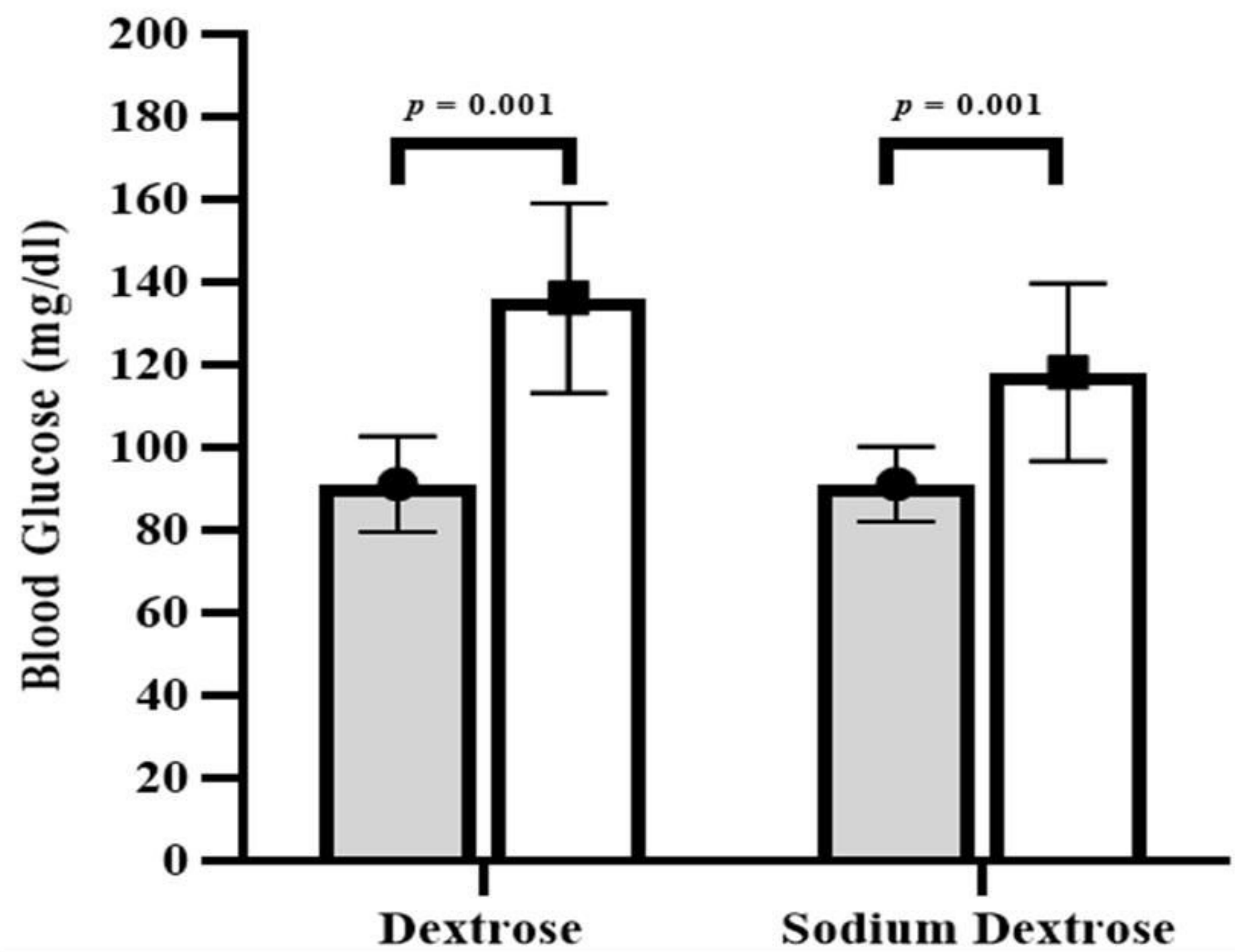

Figure 2

Blood glucose differences. Blood glucose differences before and after dextrose supplementation $(\mathrm{p}=$ $0.001)$. Blood glucose differences before and after sodium dextrose supplementation $(p=0.001)$. Shading bar: blood glucose before supplementation; white bar: blood glucose after supplementation 


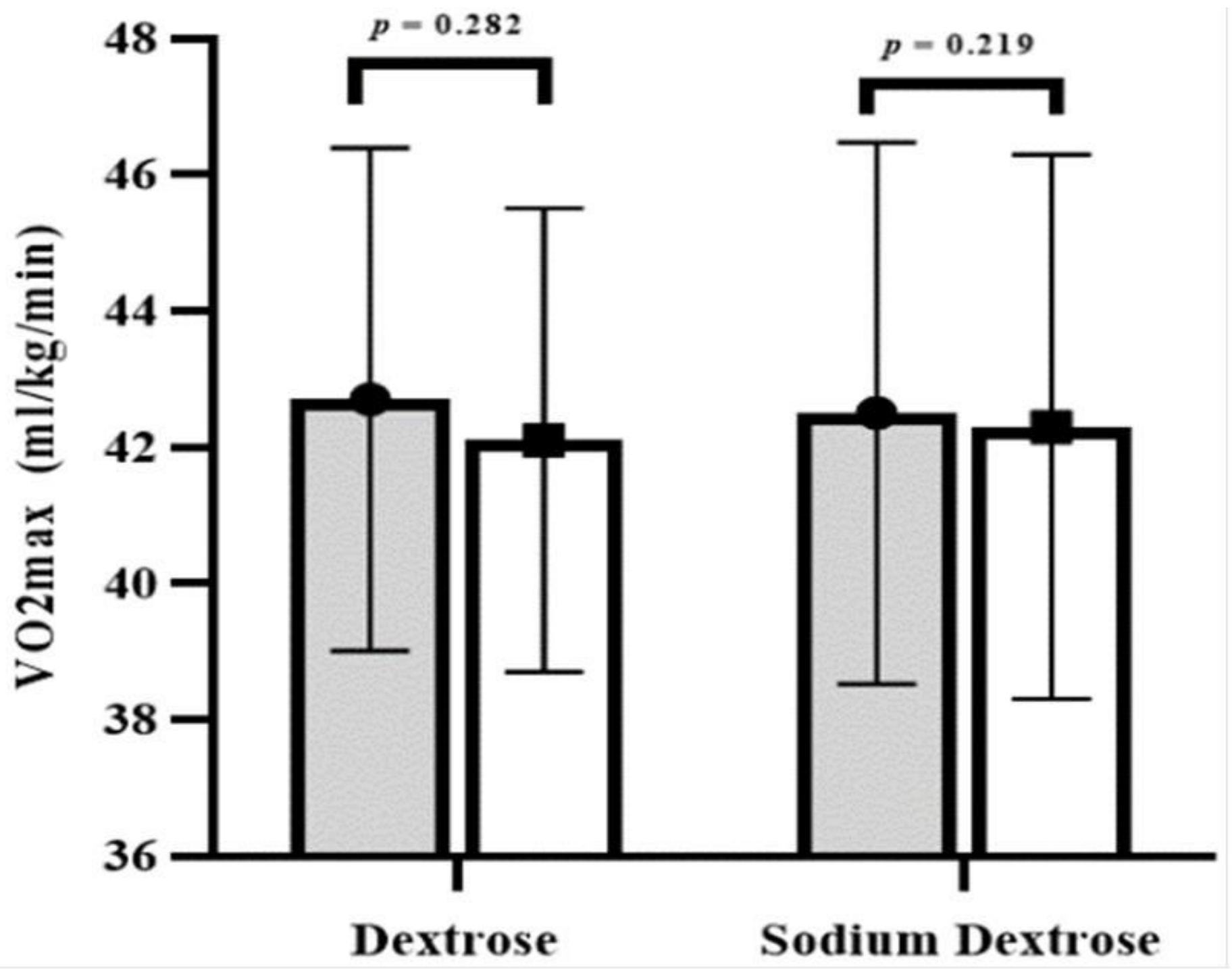

Figure 3

V02max differences. V02max differences before and after dextrose supplementation ( $p=0.282)$. V02max differences before and after sodium dextrose supplementation $(p=0.219)$. Shading bar: V02max before supplementation; white bar: VO2max after supplementation 


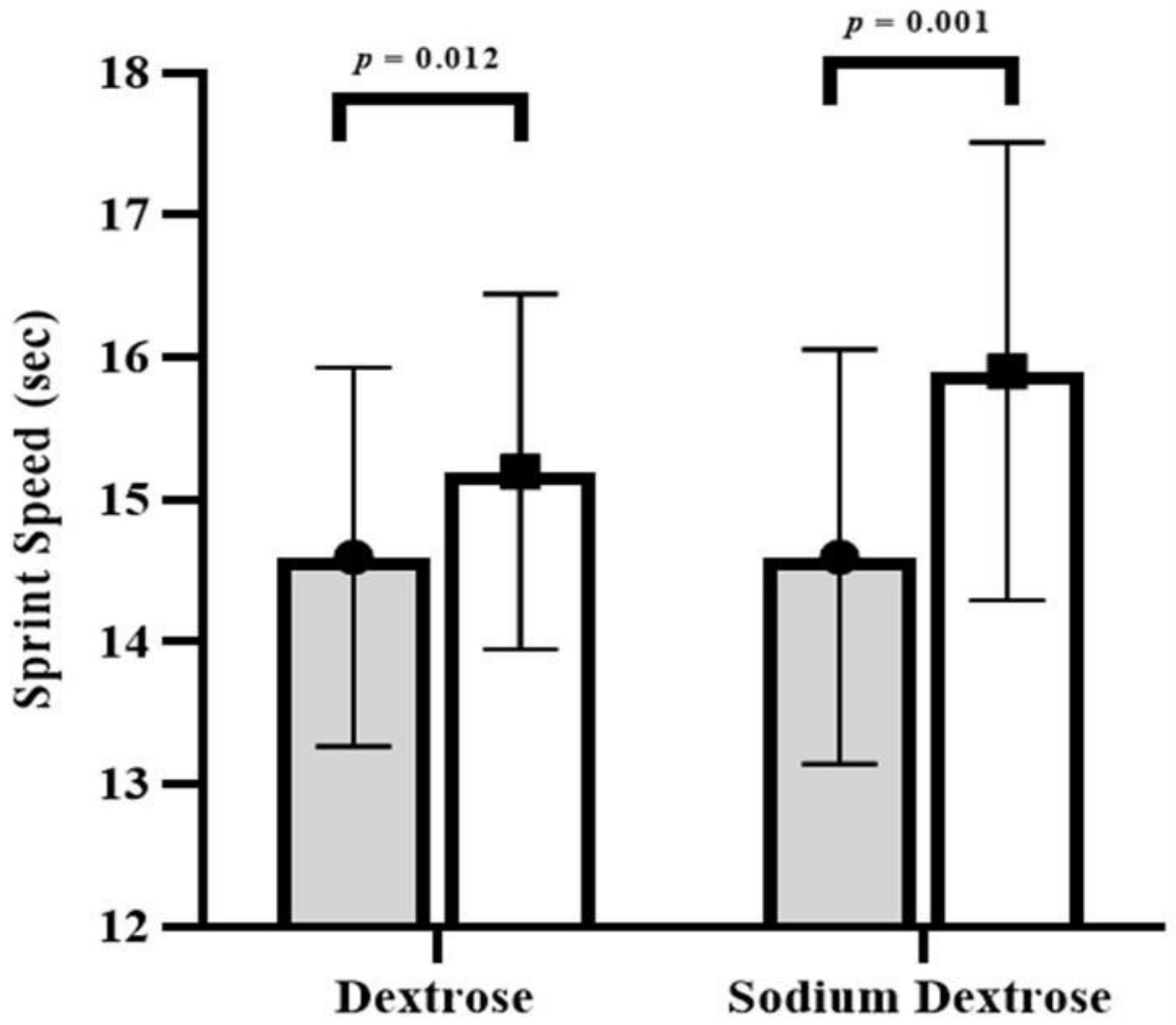

Figure 4

Sprint differences. Sprint differences before and after dextrose supplementation $(p=0.012)$. Sprint differences before and after sodium dextrose supplementation $(p=0.001)$. Shading bar: sprint speed before supplementation; white bar: sprint speed after supplementation

\section{Supplementary Files}

This is a list of supplementary files associated with this preprint. Click to download.

- XanderCONSORT.docx 